\title{
Distribution of mast cells in benign odontogenic tumors
}

\author{
Francisco de Assis Caldas Pereira • Clarissa Araújo Silva Gurgel • \\ Eduardo Antônio Gonçalves Ramos • Manuela Torres Andion Vidal • \\ Antônio Luiz Barbosa Pinheiro • Vladimir Jurisic • Caroline Brandi Schlaepfer Sales • \\ Patrícia Ramos Cury • Jean Nunes dos Santos
}

Received: 15 September 2011 / Accepted: 9 November 2011 /Published online: 30 November 2011

(C) International Society of Oncology and BioMarkers (ISOBM) 2011

\begin{abstract}
The aim of this study was to investigate the presence of mast cells in a series of odontogenic tumors. Forty-five cases of odontogenic tumors were investigated using immunohistochemistry for mast cell triptase, and differences between groups were statistically evaluated. Mast cells were present in $96 \%$ of odontogenic tumors. Mast cells present in solid ameloblastoma were observed in the tumor stroma surrounding more solid and follicular epithelial islands, with or without squamous metaplasia.
\end{abstract}

F. de Assis Caldas Pereira • C. A. S. Gurgel • M. T. A. Vidal •

J. N. dos Santos

Department of Oral Pathology, Laboratory of Surgical Pathology,

School of Dentistry, Federal University of Bahia,

Salvador, Bahia, Brazil

E. A. G. Ramos • C. B. S. Sales

Gonçalo Moniz Research Center, Oswaldo Cruz Foundation,

Salvador, Bahia, Brazil

\section{A. L. B. Pinheiro}

Center of Biophotonic, School of Dentistry,

Federal University of Bahia,

Salvador, Bahia, Brazil

V. Jurisic

School of Medicine, University of Kragujevac,

Belgrade, Serbia

P. R. Cury

Department of Periodontics, School of Dentistry,

Federal University of Bahia,

Salvador, Bahia, Brazil

J. N. dos Santos $(\square)$

Faculdade de odontologia, Laboratório de Patologia Cirúrgica, Universidade Federal da Bahia,

Avenida Araújo Pinho, 62, Canela,

Salvador, Bahia 40110-150, Brazil

e-mail: jeanunes@ufba.br
The odontogenic mixoma showed few mast cells. In odontogenic tumors with a cystic structure, the mast cells were distributed throughout all areas of the lesions, mainly in keratocystic odontogenic tumor. In addition, the total density of mast cells between all odontogenic tumors showed no significant difference $(p>0.05)$. A greater mast cells distribution was found in keratocystic odontogenic tumor in relation to adenomatoid odontogenic tumor $(p<$ 0.01 ), and when the unicystic ameloblastoma and keratocistic odontogenic tumor were compared to the odontogenic myxoma $(p<0.05)$. Syndrome keratocystic odontogenic tumor showed a higher mean of mast cells when compared with the other tumors of the sample. Mast cells values presented by syndrome keratocystic odontogenic tumor were significantly greater than those of the sporadic keratocystic odontogenic tumor that were not associated with the syndrome $(p=0.03)$. Mast cells are probably one of the major components of the stromal scaffold in odontogenic tumors. We found significant differences of mast cells between syndrome nonsyndrome keratocystic odontogenic tumors, although their distribution did not seem to have any influence on the biologic behavior of benign odontogenic tumors.

Keywords Mast cell $\cdot$ Immunohistochemistry . Odontogenic tumors $\cdot$ Ameloblastomas

\section{Introduction}

Odontogenic tumors (OTs) are derived from epithelial and/ or ectomesenchimal cells of either the forming dental organ or associated structures. They are considered to be important for both oral and maxillofacial surgery and pathology as they cause extensive bone destruction [1-4]. 
Due to significant clinical and histopathological diversity between the entities that are part of their spectrum, OTs are heterogeneous and can vary from a nonneoplastic proliferation to a benign or malignant lesion with metastatic capacity $[4,5]$.

Mast cells (MCs) are bone marrow-derived cells $[6,7]$ that are widely found in human tissues [8]. They are classified according to the secretion of proteins called endopeptidases and are divided into tryptases and chymases [9]. MCs are also considered to be important in tumorigenesis because they play a key role in the dynamics of tumor growth. These cells influence angiogenesis, tissue remodeling and a host's immunological response [10-12]. Moreover, there is evidence of an association between the density of MCs and the process of tumor development. These cells are primarily present close to the tumor, interacting with the tumoral microenvironment via surface molecules, cytokines and growth factors, effectively contributing to the progression of the tumor [10,11, 13-15].

The tissue stroma plays an essential role in the preservation of epithelial tissues as minor alterations in the epithelial tissue are followed by corresponding changes in the stroma [16]. Given that MCs may accumulate on sites at which neoplastic lesions develop and that little is known about both their role and behavior in OTs, the aim of this study was to examine the distribution of MCs present in a series of benign OTs.

\section{Material and methods}

Following approval by the Ethics Committee (Protocol number: 25/10) of the School of Dentistry of the Federal University of Bahia, 45 cases of OTs diagnosed at the Laboratory of Surgical Pathology of the School of Dentistry of the Federal University of Bahia were reviewed. Histological diagnosis were revised and classified by an experienced oral pathologist (JNS) based upon the current World Health Organization (WHO) classification [17].

The sample consisted of 10 solid ameloblastomas (SAs), 10 unicystic ameloblastomas (UAs), 10 keratocystic odontogenic tumor (KOTs: five sporadic KOTs and five syndrome KOTs), six adenomatoid odontogenic tumors (AOTs), five odontogenic mixomas (OMs), and four cystic calcifying odontogenic tumors (CCOTs).

Sections $(3 \mu \mathrm{m})$ cut and obtained from paraffinembedded specimens were deparaffinized in xylene (two times for $10 \mathrm{~min}$ ) and absolute alcohol (two times for $5 \mathrm{~min}$ ) at room temperature. For antigen retrieval of monoclonal mast cell triptase antibody (1:50, clone AA1, Novocastra Laboratories, Newcastle), the sections were treated with a $1 \%$ trypsin solution at $37^{\circ} \mathrm{C}$ for $30 \mathrm{~min}$. The endogenous peroxidase activity was blocked by using a $3 \%$ hydrogen peroxide solution for $30 \mathrm{~min}$. Next, the sections were incubated with the primary antibody diluted in antibody diluent in addition to background-reducing components (Corporation, Carpinteria, CA, USA) at $4^{\circ} \mathrm{C}$ overnight. The EnVision Polymer (Dako Corporation, Carpinteria, CA, USA) was then applied for $30 \mathrm{~min}$ at room temperature, followed by the development of the reaction with 3,3-diaminobenzidine (Dako Corporation, Carpinteria, CA, USA) as chromogen solution for $5 \mathrm{~min}$ in a dark chamber. Afterward, sections were counterstained with Harris hematoxylin. Piogenic granuloma sections were used as positive controls for the mast cell triptase. For negative control, the primary antibody was replaced by a nonimmune serum.

Histological analyses included the observation of the MCs on both stroma and the parenchyma of the tumors, avoiding areas of significant inflammation. When the MCs were observed on the parenchyma of the lesion, they were considered to be intraparenchymal. When they were located at the stroma, they were referred to as periparenchymal. However, the total count including both areas was also considered. In addition, the shape of the cells and the presence of degranulated MCs were also described.

The histomorphometric assessment was carried out by two trained observers (F.A.C.P and J.N.S) using high definition light microscopy $\times 400$ (Axiostar Plus, Zeiss, Germany, $\times 400$ ) in up to 10 high power fields using a digital camera for recording (Axiocam Icc3, Zeiss, Germany), and both observers were blind to the microscopic diagnosis and previous value of count. Mast cell count per square millimeter was performed using a specific software (Axiovision Rel 4.8, Zeiss, Germany 2008). Quantification of positive cells was calculated by the mean count found in each case.

Differences between groups were evaluated using the Kruskal-Wallis test followed by the Dunn's test and the Mann-Whitney test. All statistical calculations were performed using the GraphPad Prism 4.0 program (San Diego, USA). A $p$-value $<0.05$ was considered to be statistically significant.

\section{Results}

MCs were present in $96 \%$ of tumors, except for two ameloblastoma cases (one solid and one unicystic). Morphologically, these cells had an elongated, oval, and/or rounded shape, with brownish immunostaining, commonly located close to blood vessels. In general, MCs were primary located in the periparenchymal region of the OTs, whereas relatively fewer MCs were found within the tumor's parenchyma. A summary of the statistical analysis is seen on Table 1.

MCs present in solid ameloblastoma were observed in the tumor stroma surrounding more solid and follicular epithelial islands, with or without squamous metaplasia (Fig. 1a). The intraparenchymal MCs were seen at the 
Table 1 Distribution of MCs in benign odontogenic tumors

\begin{tabular}{|c|c|c|c|c|}
\hline Tumor & $\begin{array}{l}\text { Periparenchymal } \\
\text { count }(\text { Mean } \pm \text { SD) }\end{array}$ & $\begin{array}{l}\text { Intraparenchymal } \\
\text { count }(\text { Mean } \pm \text { SD) }\end{array}$ & $\begin{array}{l}\text { Total count } \\
(\text { Mean } \pm \text { SD) }\end{array}$ & $\begin{array}{l}\text { Periparenchymal } \times \\
\text { intraparenchymal }\end{array}$ \\
\hline Solid ameloblastoma & $2.63 \pm 1.64$ & $0.49 \pm 0.63$ & $3.02 \pm 0.63$ & $p<0.05^{\mathrm{a}}$ \\
\hline Unicystic ameloblastoma $^{\mathrm{b}}$ & $2.51 \pm 1.16$ & $0.67 \pm 0.82$ & $3.16 \pm 1.43$ & $p<0.05^{\mathrm{a}}$ \\
\hline Syndrome keratocystic odontogenic tumor ${ }^{\mathrm{b}}$ & $4.76 \pm 1.18$ & $0.26 \pm 0.37$ & $4.76 \pm 1.03$ & $p<0.05^{\mathrm{a}}$ \\
\hline Nonsyndrome keratocystic odontogenic tumor ${ }^{b}$ & $2.66 \pm 1.33$ & $0.46 \pm 0.21$ & $2.82 \pm 1.82$ & $p<0.05^{\mathrm{a}}$ \\
\hline Odontogenic myxoma & - & - & $1.30 \pm 0.26$ & - \\
\hline Adenomatoid odontogenic adenomatoid ${ }^{\mathrm{b}}$ & $0.95 \pm 0.28$ & $0.80 \pm 0.77$ & $1.75 \pm 0.62$ & $p>0.05^{\mathrm{a}}$ \\
\hline Calcifying cystic odontogenic tumor ${ }^{\mathrm{b}}$ & $1.95 \pm 0.79$ & $2.25 \pm 1.78$ & $2.76 \pm 0.66$ & - \\
\hline
\end{tabular}

${ }^{\mathrm{a}}$ Mann-Whitney test

${ }^{\mathrm{b}}$ In these lesions, the periparenchymal region corresponded to the fibrous cystic wall whereas the intraparenchymal area corresponded to the epithelial lining

periphery of the tumor islands (Fig. 1b, and Fig. 3a, c), and in areas corresponding to stellate reticulum of ameloblastomas (Fig. 1c). The OM showed few MCs (Fig. 1d), which were more frequently located next to the bone trabeculae within the tumor and adjacent to areas of bone sclerosis. Regarding OMs, MCs were exclusively seen in the extracellular matrix. In this tumor, it is not possible to establish a well-defined boundary between the tumoral stroma and the parenchyma.

In OTs with a cystic structure (KOT, UA, CCOT, and AOT), the MCs were distributed throughout all areas of the lesion including the deepest areas of the cystic capsule, the intermediate areas and the areas close to the epithelial lining mainly in KOTs (Fig. 1e-h). Those areas next to the epithelial lining showed the highest concentration of cells except when there was subepithelial hyalinization such as in UA (Fig. 2a). In addition, a few mast cells were located within the cystic epithelium (Fig. 1b, e, h, Fig. 2a, d, and Fig. 3d) and in areas close to calcification (Fig. 3b). Another finding observed was the presence of an intense degranulation process of mast cells in the vicinity of bone tissue such as those tumors presenting bone sclerosis and amidst bone trabeculae (Fig. 2c, f) except for AOT that showed an absence of MCs in those areas. Degranulated MCs were also surrounding or amidst ghost cells (Fig. 2d) as well as close to and in areas of inflammation (Fig. 1e). Further, MCs were located in and near the epithelial parenchyma of AOTs (Fig. 3a, c).
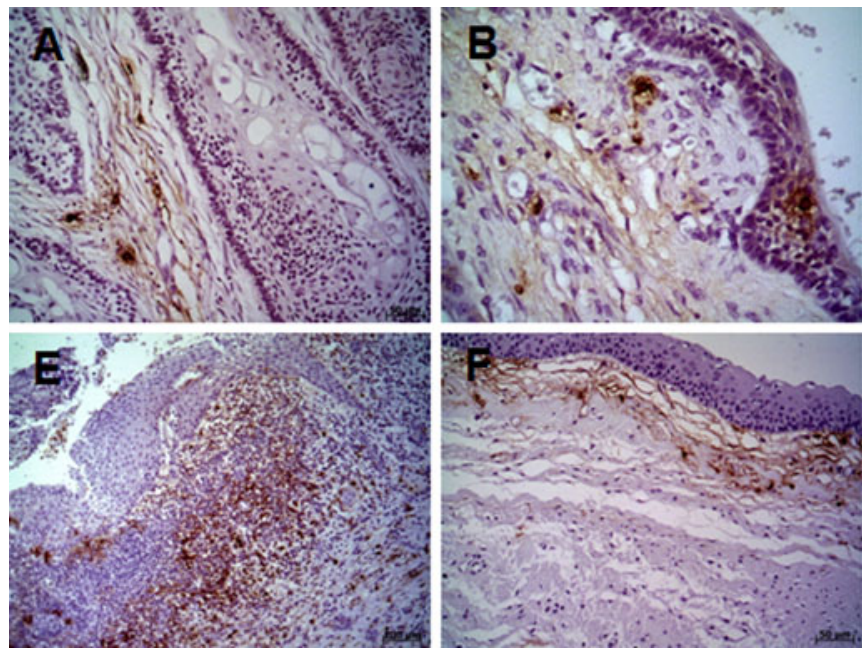

Fig. 1 Solid ameloblastoma. a MCs with elongated and angular cells along the fibrous stroma and next to tumoral islands displaying squamous metaplasia; note degranulated MCs. b Cystic area displaying mast cells within the epithelial lining and scattered in the fibrous wall. c A few MCs immersed in a sheet composed of stellate reticulumlike tumor cells. Odontogenic mixoma. d Tumor displaying rare MCs present in the extracellular matrix. Keratocystic odontogenic

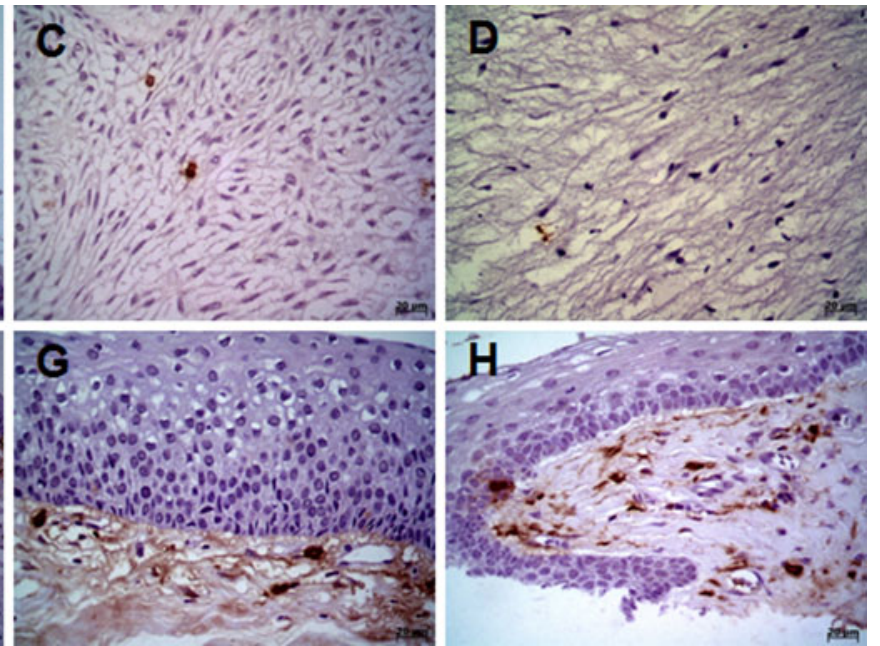

tumor. e A high number of MCs scattered throughout cystic fibrous wall that shows marked chronic inflammation. $\mathbf{f} \mathrm{MCs}$ are concentrated in the subepithelial region close to blood vessels. $\mathbf{g}$ Note MCs close to the area with a tendency to split subepithelial formation. h MCs with different shapes located along the cystic fibrous wall; note the MC located on the basal cell layer 


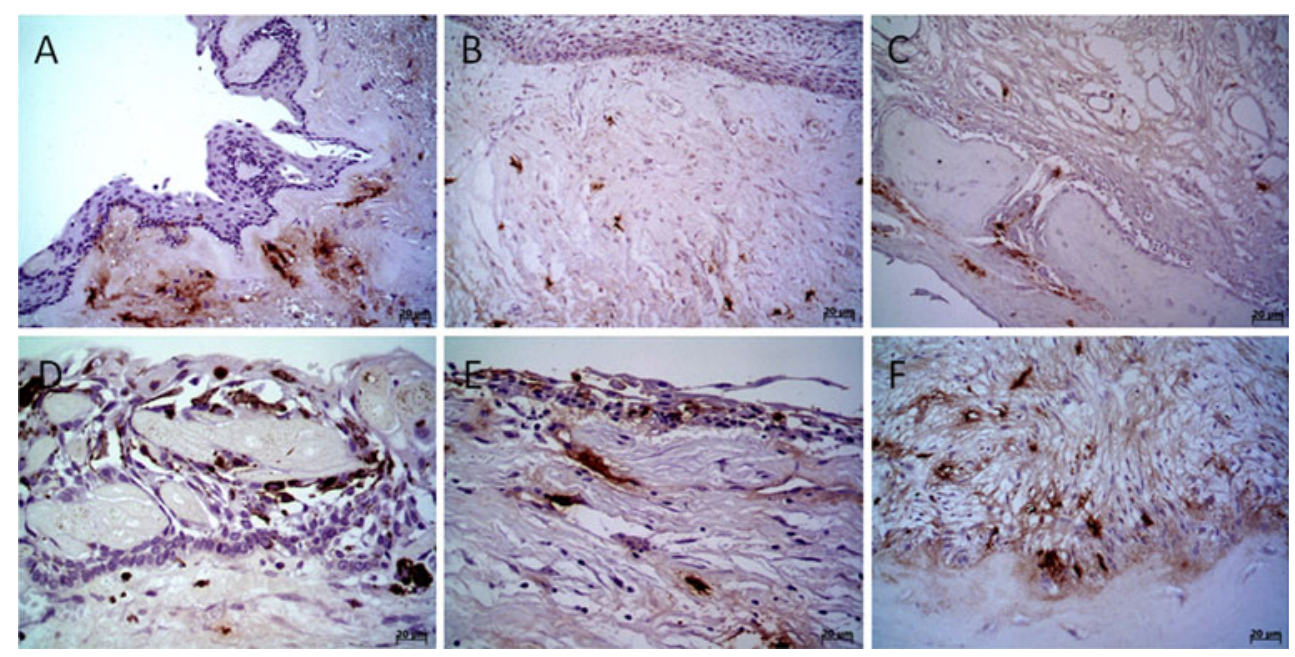

Fig. 2 Unicystic ameloblastoma. a Tumor displaying no MCs in the area corresponding to the subepithelial hyalinization. b Angular MCs close to vessels and along the cystic fibrous wall. c Degranulated MCs close to blood vessels are present in the deeper region corresponding to the cystic fibrous wall and close to bone sclerosis. Odontogenic

Using the Kruskal-Wallis test, a statistical comparison of the total density of MCs between all OTs showed no significant difference $(p>0.05)$. However, a significant difference was found when the UA and KOT were compared to the OM using the Dunn's test $(p<0.05)$ as both UA and KOT exhibited greater MCs density. Similarly, using the Mann-Whitney test, there was also no statistically significant difference when comparing the density of intraparenchymal and periparenchymal MCs. However, a greater MCs distribution was found in KOT in relation to AOT $(p<0.01)$.
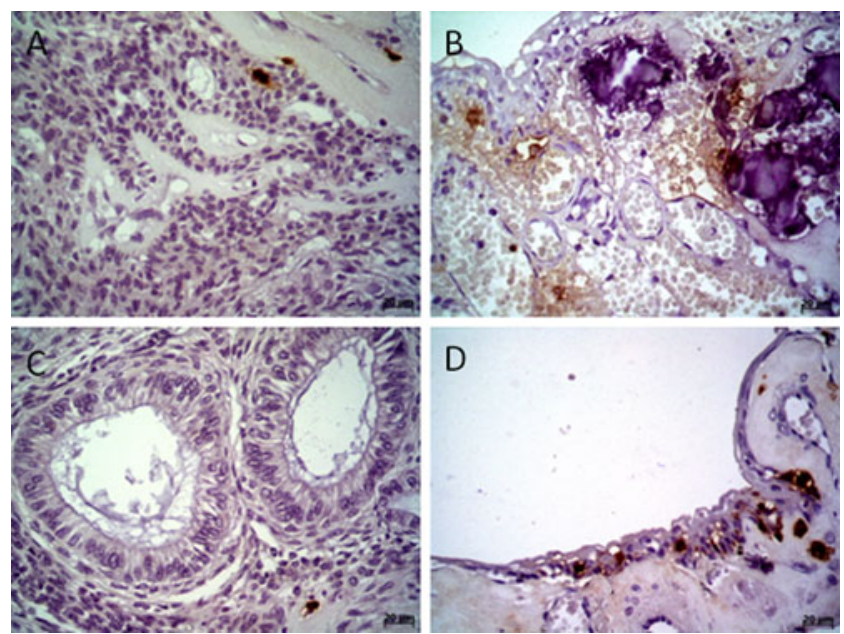

Fig. 3 Adenomatoid odontogenic tumor. a Rare MCs present within the tumor parenchyma and close to blood vessels. b Cystic area displaying a few MCs that are close to congested blood vessels and to calcification. c Small cluster of MC next to the ductlike structure. d Cystic area displaying MCs within the cystic epithelial lining and a few located in the subepithelial region calcifying cystic tumor. d Several MCs surrounding the ghost cells. e Cystic area with several MCs located within the epithelial lining and along the cystic wall fibrous. $\mathbf{f} \mathrm{A}$ high number of MCs along the cystic fibrous wall and close to bone sclerosis

Syndrome KOTs showed a higher mean of MCs when compared with the other tumors of the sample. As shown in Table 1, using a Mann-Whitney test, MC values presented by syndrome KOTs were significantly greater than those of the sporadic KOTs that were not associated with the syndrome $(p=0.03)$. However, when the intraparenchymal and periparenchymal areas were compared to the two forms of KOTs in a Mann-Whitney test, no significant difference was found $\left(I_{\text {intraparenchymal }}=0.6 ; P_{\text {periparenchymal }}=0.09\right.$, Mann Whitney test). It is worth noting that cases of OMs and AOT showed a lower number of MCs (Table 1).

In general, the presence of MCs in different types of OTs was weakly associated with a significant inflammatory response as no case of inflammation was detected in $24(51 \%)$ of the 45 tumors. Further, of the 23 cases that showed some typical histological sign of acute or chronic inflammation, 19 were considered to be nonsignificant. Regarding all odontogenic tumors, significant inflammation was only observed in two cases of KOT cases (Fig. 1e).

\section{Discussion}

Tumor development represents dynamic processes, which are regulated by molecular changes induced by tumor cells themselves as well as by favorable microenvironmental conditions that provide essential "tools" for survival and cell multiplication including certain cytokines, growth factors and cellular components such as MCs [14, 18]. Due to these functions, we believe that the MCs may also play an important role in the growth and expansion of OTs. 
In addition, the presence of these cells in KOTs was described in a previous report by our group [19].

In the present study, MCs were found in $96 \%$ of the OTs analyzed. Depending upon their location and stage of maturation, MCs express different quantities of surface antigens that are involved in cell activation and recognition [20]. Further, the secretion of endopeptidases by MCs modulates inflammation, matrix destruction, tissue remodeling, and angiogenesis [10-12, 21].

We found that the MCs were most frequently located in the periparenchymal region, whereas relatively fewer were observed within the tumor parenchyma. According to Maltby et al. [10], the location of MCs in periparenchymal regions of tumors suggests that the recruitment of these cells might occur due to their migration from healthy surrounding tissues or from the migration of progenitors of MCs via blood vessels close to the tumor. The extracellular matrix might also influence this finding as MCs have a high affinity for the adsorption to fibronectin induced by stem cell factor (SFC) or from integrin receptors [22-24]. In addition, several researchers have reported the presence of fibronectin in the extracellular matrix of OTs [25-27].

Regarding cystic odontogenic neoplasms, we found a greater concentration of MCs in the subepithelial region of the cystic fibrous wall when compared with deeper or more distant areas in relation to the cystic lining. These results are in agreement with previous reports [28, 29]. These findings might be due to the greater accumulation of heparin in the extracellular matrix found in this region, which could serve as a source of proangiogenic substances through the secretion of vascular endothelial growth factor (VEGF) and fibroblast growth factor-2 (FGF2) [20, 28]. In addition, we also observed the presence of MCs within the cystic lining. It is possible that the matrix proteins [28] and fibrogenic cytokines $[30,31]$ secreted by cystic odontogenic epithelium have a chemotactic effect on mast cells and facilitate their accumulation. Furthermore, degranulated MCs surrounding ghost cells within the OCCT cystic lining might indicate tumor rejection based on the enzyme content present in MCs.

The presence of MCs close to blood vessels is a common finding (14), and this was observed in this study. Despite this finding, there appears to be intimate cellular communication between this cell population and the tumor vascular system, creating a microenvironment that is favorable to neoplasic development at the expense of signaling molecules that govern the biology of MCs in tumorigenesis. In addition, some authors have observed a strong association between the presence of substances largely secreted by angiogenic factors and development of OTs $[32,33]$.

MCs are crucial in the process of remodeling the extracellular matrix in neoplastic alterations as they produce and release proteolytic enzymes favoring the migration of both endothelial and tumoral cells as well as the release of angiogenic factors stored in the within of stromal tissue. [6, 34-36]. Moreover, the MCs participate in the process of bone remodeling of odontogenic lesions through the degranulation of their enzyme content in the vicinity of bone tissue present in these lesions, which contributes to their growth and expansion [29]. Despite these roles, our findings are consistent with the observations of Teronen et al. [29] as we found a high number of degranulated MCs close to areas of bone sclerosis and amidst bone trabeculae in SA, KOT, OM, and CCOT. It is possible that the upregulation of IL17 released by MCs that infiltrate the tumor may also play a key role in remodeling the tumor microenvironment [37] although other authors believe that the MCs play no role in this process [38].

The MCs have been implicated in the formation of fibrous tissue found in the capsule of the cystic lesions because of their role in collagen synthesis from the release of substances such as heparin, hyaluronic acid, proteoglycans, proteolytic enzymes and fibroblast growth factor [39-42]. In this study, we observed the presence of MCs in the fibrous capsule of all cystic tumors even though we did not find significant differences in the density of MCs when the different types of tumors were compared. However, we believe that this study provides data to support the hypothesis that MCs influence the growth and expansion of OTs through the synthesis of collagen.

In this study, although we avoided areas of inflammation, we did not observe an association between the quantity of MCs and the presence of a significant inflammatory process. These results corroborate the findings of Smith et al. [28] who also found no relationship between the presence of these cells and inflammation present in KOTs. Our results might also partially explain those by Mitrou et al. [33] who did not observe a positive correlation between the expression of VEGF, a potent angiogenic mediator secreted largely by MCs, and inflammation in lesions of KOTs.

We did not find a statistically significant difference between all OTs and MCs. However, it is important to state that there is a clear association between the accumulation of MCs and the processes of tumor growth and progression, which are usually associated with poor prognosis $[10,13$, 14, 43-45]. This might explain the statistically significant difference in total MC count between the two forms of KOT, higher in the syndrome KOT. Syndrome KOT is more commonly related to a higher degree of aggressiveness and bone destruction when compared with the sporadic nonsyndromic type [46].

Solid ameloblastoma is considered to be more aggressive than UA [47, 48]. However, the results of 
this study did not show a significant distinction for MCs, considering the biological behavior of both lesions. We did not observe significant differences in the density of total MCs in both solid and UA even when the intraparenchymal and peritumoral areas were considered separately.

$\mathrm{OM}$ is a benign and invasive neoplasia, with a high potential for bone destruction and recurrence [1, 49]. In this study, this tumor showed a smaller amount of MCs when compared to the tumors with similar clinical behavior such as ameloblastoma and KOT. Nevertheless, this difference was only significant when compared with the KOT. This corroborates the findings of Martínez-Mata et al. [50] who also did not observe any high densities of these cells in OM. According to these latter authors, the MCs are associated with the remodeling of the extracellular matrix and a higher degree of aggressiveness of OM. Although other parameters should be studied to contribute to the data about the biological behavior of OM, this study showed that there was a significant difference in $\mathrm{MC}$ count between $\mathrm{UA}$ and $\mathrm{OM}$.

In this study, the AOT displayed a low number of MCs. This is a noninvasive benign tumor that is less aggressive. In addition, many authors consider it to be a hamartoma [51-53]. In this regard, our results corroborate the findings of Zaitoun and Triantfyllou [54] who also observed the presence of low amounts of MCs in a hamartomatous lesion of smooth muscle. Moreover, the absence of MCs in the areas of bone sclerosis could explain the nonaggressive behavior of this lesion as there would be an insufficient amount of proteolytic enzymes capable of destroying the extracellular matrix involved.

Despite the low number of CCOT cases, we also observed a concentration of MCs in the epithelial layer, especially surrounding ghost cells. Despite all cystic OTs in which MCs were found within the cystic epithelial lining, it is possible that there was a greater amount of antigenpresenting molecules expressed by the MCs in the region involved in cell activation and recognition [10]. Therefore, considering the OTs as a group of lesions with heterogeneous morphology, one might think that the function of MCs could vary with the type of tumor and its morphological characteristics.

In conclusion, mast cells are probably one of the major components of the stromal scaffold in odontogenic tumors. In addition, we found significant differences of mast cells between syndrome nonsyndrome keratocystic odontogenic tumors, although their distribution did not seem to have any influence on the biologic behavior of benign odontogenic tumors. Further studies should be carried out to try to establish a correlation between this cell population and other stromal components present in OTs, especially those involving angiogenesis.
Acknowledgements This study was supported by Conselho Nacional de Desenvolvimento Científico e Tecnológico (CNPq).

Conflict of interest None.

\section{References}

1. Santos JN, Pinto LP, de Figueredo CR, Souza LB. Odontogenic tumors: analysis of 127 cases. Pesqui Odontol Bras. 2001;15:30813.

2. Jing W, Xuan M, Lin Y, Wu L, Liu L, Zheng X, Tang W, et al. Odontogenic tumours: a retrospective study of 1642 cases in a Chinese population. Int J Oral Maxillofac Surg. 2007;36:20-5.

3. Luo HY, Li TJ. Odontogenic tumors: a study of 1309 cases in a Chinese population. Oral Oncology. 2009;45:706-11.

4. Tawfik MA, Zyada MM. Odontogenic tumors in Dakahlia, Egypt: analysis of 82 cases. Oral Surg Oral Med Oral Pathol Oral Radiol Endod. 2010;109:67-73.

5. Ledesma-Montes C, Mosqueda-Taylor A, Carlos-Bregni R, de Leon ER, Palma-Guzmán JM, Páez-Valencia C, Meneses-Garcia A. Ameloblastomas: a regional Latin-American multicentric study. Oral Dis. 2000;13:303-7.

6. Rodewald HR, Dessing M, Dvorak AM, Galli SJ. Identification of a committed precursor for the mast cell lineage. Science. 1996;271:818-22.

7. Chen CC, Grimbaldeston MA, Tsai M, Weissman IL, Galli SJ. Identification of mast cell progenitors in adult mice. Proc Natl Acad Sci USA. 2005;102:11408-13.

8. Fukushima H, Ohsawa M, Ikura Y, Naruko T, Sugama Y, Suekane $\mathrm{T}$, Kitabayashi $\mathrm{C}$, et al. Mast cells in diffuse large B-cell lymphoma; their role in fibrosis. Histopathology. 2006;49:498 505.

9. Caughey GH. Mast cell tryptases and chymases in inflammation and host defense. Immunol Rev. 2007;217:141-54.

10. Maltby S, Khazaie K, McNagny KM. Mast cells in tumor growth: angiogenesis, tissue remodelling and immune-modulation. Biochim Biophys Acta. 2009;1796:19-26.

11. Norrby K. Mast cells and angiogenesis. APMIS. 2002;110:355-71.

12. Mangia A, Malfettone A, Rossi R, Paradiso A, Raniere G, Simone G, Restal L. Tissue remodeling in breast cancer: human mast cell tryptase as an initiator of myofibroblasts differentiation. Histopathology. 2011;58:1096-106.

13. Ch'ng S, Wallis RA, Yuan L, Davis PF, Tan ST. Mast cells and cutaneous malignancies. Mod Pathol. 2006;19:149-59.

14. Conti P, Castellani ML, Kempuraj D, Salini V, Vecchiet J, Tete S, Mastrangelo F, Perrella F, et al. Role of mast cells in tumor growth. Ann Clin Lab Sci. 2007;37:315-22.

15. Ribatti D, Crivellato E, Molica S. Mast cells and angiogenesis in haematological malignancies. Leuk Research. 2009;33:876-9.

16. De Wever O, Mareel M. Role of tissue stroma in cancer cell invasion. J Pathol. 2003;200:429-47.

17. Barnes L, Eveson JW, Reichart P, Sidransky D. World Health Organization of tumours, pathology \& genetics, head and neck tumours. Lyon: IARC press; 2005.

18. Alaeddini M, Salah S, Dehghan F, Eshghyar N, EtemadMoghadam S. Comparison of angiogenesis in keratocystic odontogenic tumours, dentigerous cysts and ameloblastomas. Oral Dis. 2009;15:422-7.

19. Silva Gurgel CA, Gonçalves Ramos EA, Araújo Melo L, Brandi Schlaepfer C, de Souza RO, Campos Oliveira M, Santos JN. Immunolocalisation of laminin-1 in keratocystic odontogenic tumors. Acta Histochem. 2010;112:624-9.

20. Valent P, Schernthaner GH, Sperr WR, Fritsch G, Agis H, Willheim M, Buring HJ, et al. Variable expression of activation- 
linked surface antigens on human mast cells in health and disease. Immunol Rev. 2001;179:74-81.

21. Huttunen M, Harvima IT. Mast cell tryptase and chymase in chronic leg ulcers: chymase is potentially destructive to epithelium and is controlled by proteinase inhibitors. Br J Dermatol. 2005;152:1149-60.

22. Wayner A, Carter G, Piotrowicz S, Kunick TJ. The function of multiple extracellular matrix receptors in mediating cell adhesion to extracellular matrix: preparation of monoclonal antibodies to the fibronectin receptor that specifically inhibit cell adhesion to fibronectin and react with platelet glycoproteins Ic-IIa. J Cell Biol. 1988;107:1881-91.

23. Dastuch J, Costa J, Thompson H, Metcalf TD. Mast cell adhesion to fibronectin. Immunology. 1991;73:478-84.

24. Dastych J, Metcalfe DD. Stem cell factor induces mast cell adhesion to fibronectin. J Immunol. 1994;152:213-9.

25. Santos JN, De Souza VF, Azevêdo RA, Sarmento VA, Souza LB. Braz "Hybrid" lesion of desmoplastic and conventional ameloblastoma: immunohistochemical aspects. Braz J Otorhinolaryngol. 2006;72:709-13.

26. Poomsawat S, Punyasingh J, Vejchapipat P. Expression of basement membrane components in odontogenic tumors. Oral Surg Oral Med Oral Pathol Oral Radiol Endod. 2007;104:666-75.

27. de Medeiros AM, Nonaka CF, Galvão HC, de Souza LB, Freitas RA. Expression of extracellular matrix proteins in ameloblastomas and adenomatoid odontogenic tumors. Eur Arch Otorhinolaryngol. 2010;267:303-10.

28. Smith G, Smith AJ, Basu MK. Mast cells in human odontogenic cysts. J Oral Pathol Med. 1989;18:274-8.

29. Teronen O, Hietanen J, Lindqvist C, Salo T, Sorsa T, Eklund KK, Sommerhoff CP, et al. Mast cell-derived tryptase in odontogenic cysts. J Oral Pathol Med. 1996;25:376-81.

30. Roberts IS, Brenchley PE. Mast cells: the forgotten cells of renal fibrosis. J Clin Pathol. 2000;53:858-62.

31. Li CY, Baek JY. Mastocytosis and fibrosis: role of cytokines. Int Arch Allergy Immunol. 2002;127:123-6.

32. Kumamoto H, Ooya K. Immunohistochemical detection of platelet-derived endothelial cell growth factor/thymidine phosphorylase and angiopoietins in ameloblastic tumors. J Oral Pathol Med. 2006;35:606-12.

33. Mitrou GK, Tosios KI, Kyroudi A, Skalavounou A. Odontogenic keratocyst expresses vascular endothelial growth factor: an immunohistochemical study. J Oral Pathol Med. 2009;38:470-5.

34. Stack M, Johnson D. Human mast cell tryptase activates singlechain urinary-type plasminogen activator. J Biol Chem. 1994;269:9416-19.

35. Reed J, McNutt N, Bogdany J, Albino AP. Expression of the mast cell growth factor interleukin-3 in melanocytic lesions correlates with an increased number of mast cells in the perilesional stroma: implications for melanoma progression. J Cutan Pathol. 1996;23:495-505.

36. Ribatti D, Vacca A, Ria R, Marzullo A, Nico B, Filotico R, Roncali L, et al. Neovascularization, expression of fibroblast growth factor-2, and mast cells with tryptase activity increase simultaneously with pathological progression in human malignant melanoma. Eur J Cancer. 2003;39:666-74.
37. Fossiez F, Banchereau J, Murray R, Van Kooten C, Garrone $\mathrm{P}$, Lebecque $\mathrm{S}$. Interleukin-17. Int Rev Immunol. 1998; 16:541-51.

38. Yang Z, Zhang B, Li D, Huang C, Shen GX, Huang B. Mast cells mobilize myeloid-derived suppressor cells and Treg cells in tumor microenvironment via IL-17 pathway in murine hepatocarcinoma model. PLoS ONE. 2010;5:e8922.

39. Ahmed A, Powers MP, Youker KA, Rice L, Ewton E, Dunphy $\mathrm{CH}$, Chang CC. Mast cell burden and reticulin fibrosis in the myeloproliferative neoplasms: a computer-assisted image analysis study. Pathol Res Pract. 2009;205:634-8.

40. Fujiwara H, Konno R, Netsu S, Sugamata M, Ohwada M, Suzuki M. Localization of mast cells in endometrial cysts. Am J Reprod Immunol. 2004;51:341-4.

41. Drazić R, Sopta J, Minić AJ. Mast cells in periapical lesions: potential role in their pathogenesis. J Oral Pathol Med. 2010;39:257-62.

42. Farahani SS, Navabazam A, Ashkevari FS. Comparison of mast cells count in oral reactive lesions. Pathol Res Pract. 2010;206:151-5.

43. Duncan L, Richards L, Mihm Jr M. Increased mast cell density in invasive melanoma. J Cutan Pathol. 1998;25:11-5.

44. Humphreys TR, Monteiro MR, Murphy GF. Mast cells and dendritic cells in basal cell carcinoma stroma. Dermatol Surg. 2000;26:200-3. discussion 203-4.

45. Ribatti D, Ennas MG, Vacca A, Ferreli F, Nico B, Orru S, Sirigu P. Tumor vascularity and tryptase-positive mast cells correlate with a poor prognosis in melanoma. Eur J Clin Invest. 2003;33 (5):420-5.

46. Madras J, Lapointe H. Keratocystic odontogenic tumour: reclassification of the odontogenic keratocyst from cyst to tumour. Tex Dent J. 2008;125:446-54.

47. Carlson ER, Marx RE. The ameloblastoma: primary, curative surgical management. J Oral Maxillofac Surg. 2006;64:484-94.

48. Pogrel MA, Montes DM. Is there a role for enucleation in the management of ameloblastoma? Int $\mathrm{J}$ Oral Maxillofac Surg. 2009;38:807-12.

49. Jaeger M, Santos J, Domingues M, Ruano R, Araújo N, Caroli A, Jaeger R. A novel cell line that retains the morphological characteristics of the cells and matrix of odontogenic myxoma. J Oral Pathol Med. 2000;29:129-38.

50. Martínez-Mata G, Mosqueda-Taylor A, Carlos-Bregni R, de Almeida OP, Contreras-Vidaurre E, Vargas PA, Cano-Valdez $\mathrm{AM}$, et al. Odontogenic myxoma: clinico-pathological, immunohistochemical and ultrastructural findings of a multicentric series. Oral Oncol. 2008;44:601-7.

51. Rick GM. Adenomatoid odontogenic tumor. Oral Maxillofac Surg Clin N Am. 2004;16:333-54.

52. Santos JN, Lima FO, Romério P, Souza VF. Adenomatoid odontogenic tumor: an unusual case exhibiting cribriform aspect. Quintessence Int. 2008;39:777-81.

53. Garg D, Palaskar S, Shetty VP, Bhusham A. Adenomatoid odontogenic tumor - hamartoma or true neoplasm: a case report. J Oral Sci. 2009;51:155-9.

54. Zaitoun H, Triantfyllou A. Smooth muscle hamartoma of the hard palate. J Oral Pathol Med. 2007;36:245-9. 